Research Article

\title{
Evaluation of Antimicrobial Activity of Conyza bonariensis Leaf Extracts against Clinically Isolated Fungi Causing Superficial Infection
}

\author{
Yidnekachew Girma ${ }^{1}$ and Tamene Milkessa Jiru $\mathbb{D}^{2}$ \\ ${ }^{1}$ Department of Biotechnology, Institute of Biotechnology, University of Gondar, P.O.Box:196, Gondar, Ethiopia \\ ${ }^{2}$ Department of Environmental and Industrial Biotechnology, Institute of Biotechnology, University of Gondar, \\ P.O.Box:196, Gondar, Ethiopia
}

Correspondence should be addressed to Tamene Milkessa Jiru; tamene1971@gmail.com

Received 13 October 2021; Accepted 25 October 2021; Published 5 November 2021

Academic Editor: Liviu Mitu

Copyright (c) 2021 Yidnekachew Girma and Tamene Milkessa Jiru. This is an open access article distributed under the Creative Commons Attribution License, which permits unrestricted use, distribution, and reproduction in any medium, provided the original work is properly cited.

\begin{abstract}
Plants have been used since long time ago to treat infectious diseases and are considered as important sources of new antimicrobial agents. In this study, crude extracts from leaves of Conyza bonariensis were prepared using methanol, ethyl acetate, hexane, and chloroform. Antimicrobial activity of the extracts was evaluated against pathogenic fungi causing superficial infection (Candida albicans, Malassezia globosa, and Malassezia furfur). Results demonstrated that all extracts had different effects against all the tested fungi with the exception of crude extract using hexane which did not show any effect against $M$. furfur. A strong effect was observed with chloroform and hexane extracts on C. albicans $(32.60 \pm 4.69 \mathrm{~mm}$ and $27.00 \pm 1.00 \mathrm{~mm})$, respectively. While, ethyl acetate and methanol extracts showed the best effect against $M$. furfur $(30.80 \pm 1.71 \mathrm{~mm}$ and $27.00 \pm 1.00 \mathrm{~mm})$, respectively. Moreover, the ethyl acetate showed a considerable effect on $M$. globosa $(25.03 \pm 1.05 \mathrm{~mm})$. Minimum inhibitory concentration (MIC) of the fractions was also determined by the microbroth dilution method. The results recorded as the MIC values of the tested extracts against fungi varied from $0.19 \pm 0.00$ to $66.66 \pm 2.86 \mathrm{mg} / \mathrm{mL}$. Ethyl acetate was the best and powerful extract with the lowest MIC value of $0.190 .19 \pm 0.00 \mathrm{mg} / \mathrm{mL}$ for all tested fungi followed by chloroform and methanol extracts with the MIC values ranging from $0.19 \pm 0.00$ to $0.78 \pm 0.00 \mathrm{mg} / \mathrm{mL}$ and $0.84 \pm 0.68$ to $1.56 \mathrm{mg} / \mathrm{mL}$, respectively. Concerning minimum bactericidal concentration (MFC), ethyl acetate was the most potent extract with a MFC value of $0.190 .19 \pm 0.00 \mathrm{mg} / \mathrm{mL}$ for C. albicans and M. furfur. Higher $(0.39 \mathrm{mg} / \mathrm{mL}) \mathrm{MFC}$ was recorded against $M$. globosa by this extract. In conclusion, solvent extracts of some C. bonariensis can be used to treat infections with pathogenic fungi such as C. albicans, M. furfur, and M. globosa. Further studies should consider this plant as one of the best candidates for the discovery of potent antimicrobial compounds that treat superficial infections.
\end{abstract}

\section{Introduction}

According to the WHO [1], traditional medicine is defined as health practice, approach, knowledge, and beliefs incorporating plant, animal, and mineral-based medicines, spiritual therapies, manual techniques, and exercises applied singularly or in combination to treat, diagnose, and prevent illness or maintain wellbeing. Traditional medicine and medicinal plants have been employed by the majority of the world population for thousands of years. According to fossil records, the human use of plants as medicines may be drawn back at least 60,000 years [2]. Until the establishment of the $19^{\text {th }}$ century, all medicines were traditional. Yet, in several developing countries, it is true that for the majority of rural population, traditional medicine is the only primary medicine for healthcare [3]. Medicinal plants have provided good sources of antimicrobial agents against several infectious pathogens including bacteria and fungi [4].

Either due to limited availability or affordability of pharmaceutical medicines, about $80 \%$ of the rural 
population in sub-Saharan Africa depends on traditional herbal therapies for primary healthcare [1]. Similarly, in Ethiopia, $80 \%$ of the population depends on the use of traditional medicine [5]. Furthermore, Ethiopia is one of the six countries of the world where about $60 \%$ of plants with healing potential are said to be indigenous [6]. The country is believed to be a home for approximately 6,500 species of higher plants with about $12 \%$ endemic, hence making it one of the six plant biodiversity-rich countries of Africa [7,8], and the country has a long history of using medicinal plants to treat a variety of human ailments [9].

Ethiopia is with a wealth of unexplored natural products, and it is an ideal place to search for new medicine for the treatment of infectious diseases. Eventhough some studies have been conducted to explore the antimicrobial potential of various medicinal plants, these studies are insufficient as compared to the current widespread problem and prevalence of drug resistance microbe as well as the urgent needs of new medicine $[10,11]$.

The skin being the outermost and first line of protection is simply exposed to physical agents and different pathogens leading to several infections [12]. Fungal pathogens commonly dermatophytes or superficial mycotic fungi of humans and animals not only infect the keratinized tissues of the skin but also infect nails and hairs [13]. They are most likely found in hot humid areas. These fungi can easily digest the keratinized tissue by releasing sulphite, exoprotease, and endoprotease [13]. Sulphite being a reducing agent broke the disulphide bonds of keratin protein and made them more vulnerable to fungal proteases enzymes. Human infections, particularly those involving the skin and mucosal surface constitute a serious problem, especially in tropical and subtropical developing countries, dermatophytes and Candida sp., being the most frequent pathogens.

C. albicans is an opportunistic fungal pathogen of humans. Although a normal part of our gastrointestinal flora, vagina, and mucosal cavity, C. albicans has the ability to colonize nearly every human tissue and organ, causing serious, invasive infections [14]. C. albicans is a normal resident of the human gastrointestinal tract; it is also the most common fungal pathogen of humans, causing both mucosal and systemic infections, particularly in immunocompromised or whose natural flora has been altered patients [15]. Candida species are yeast-type fungi. C. albicans is the most common pathogen among the Candida species [16]. Lesions caused by C. albicans appear as white patches on the skin or mucus membrane, hence the name $C$. albicans. Other species within this genus that cause disease include C. glabrata, C. guilliermondii, C. krusei, C. parapsilosis, and C. tropicalis [17]. Phytochemical extracts from medicinal plants have been used to treat infectious diseases such as candidiasis in developing world [18]. Study reports from Pramila et al.[19] and Hussein et al. [20] showed that herbal extracts are generally effective against C. albicans.

Tinea versicolor also known as pityriasis versicolor is a condition characterized by a skin eruption on the trunk and proximal extremities. A yeast-like fungus called M. globosa is the major cause of tinea versicolor. M. furfur is another causative agent for this disease [21, 22]. Both yeasts are normally found on the human skin and become troublesome only under certain circumstances, such as a warm and humid environment [21, 23].

Dandruff is a skin condition that mainly affects the scalp. Symptoms include flaking and itchy scalp [24] and inflammation of the skin (seborrhoeic dermatitis) [25]. Red and greasy patches of the skin and a tingly feeling on the skin are also symptoms. The responsible microorganism that affects the scalp is a fungus, M. furfur [26]. This disease is also caused by other fungi, namely, M. globosa [27] and $M$. restricta [28]. M. globosa metabolizes triglycerides present in sebum by the expression of lipase, resulting in a lipid byproduct oleic acid [27].

Natural products such as extracts and essential oils from native plants have been important sources of products for the developing countries in treating common infections including fungal diseases. Some studies have demonstrated that the plant extract has been used traditionally to treat a number of infectious diseases caused by bacteria and fungi [13].

The species of Conyza have a great capacity of adaptability, which allows them to occur in different soil and climatic conditions [29]. C. bonariensis, which is an annual or short-lived perennial weed of the Asteraceae family [30], is widely used as a folk medicine in the treatment of rheumatism, gout, cystitis, nephritis, dysmenorrhea, tooth pain, and headache; it is also reported to have an antiulcerogenic and anticoagulant activity [31]. C. bonariensis is also used to treat a variety of skin conditions [32].

Due to the availability of rich biodiversity and highly unexplored natural resources in Ethiopia, focusing on searching for novel, highly effective, better active, safe, and affordable antimicrobial agents must be prior activity. Screening using in vitro evaluation is a useful tool for the discovery of new potential antifungal agents from natural products such as essential oils and extracts derived from plants. Therefore, the current study is aimed at evaluating the antimicrobial potential of $C$. bonariensis leaf extract against selected human pathogenic fungi causing superficial infection.

\section{Materials and Methods}

2.1. Study Area and Period. The current study was conducted at Tewodros Campus, Microbiology Laboratory, Institute of Biotechnology, University of Gondar, Gondar town, Northwest Ethiopia. Gondar town is located $738 \mathrm{Km}$ away from Addis Ababa, capital city of Ethiopia. The town has $12^{\circ} \mathrm{C} 36^{\prime}$ north latitude and $37^{\circ} \mathrm{C} 28^{\prime}$ east longitude with an elevation of 2133 meter above sea level. Average maximum and minimum temperature is $29^{\circ} \mathrm{C}$ (in March and May) and $10^{\circ} \mathrm{C}$ (in January and December), respectively. The mean relative humidity for an average year is recorded as $55.7 \%$, and on monthly basis, it ranges from $40 \%$ in January to $79 \%$ in July. According to a report by CSA [33], Gondar has a population of 299,969.

2.2. Study Design. An in vitro experimental laboratory-based study was conducted from January to September 2019 to evaluate antimicrobial activity of leaf extracts of the plant C. bonariensis against available clinical fungal pathogens. 
2.3. Plant Material Collection and Identification. Leaves of C. bonariensis plant were collected from Gondar City in University of Gondar compound. Normally, noncontaminated and nondiseased leaves were used for the study (Figure 1). The plant leaves were selected based on the information given by local traditional healers (practitioners) in the area, Gondar town. Taxonomical identification and verification were performed at Department of Biology by Mr. Abiyou Eniyew, a Botanist, College of Natural and Computational Sciences, University of Gondar. Last, voucher of the specimen with deposition number 001/YGL/ 2019 was deposited in the College of Natural and Computational Sciences Herbarium, University of Gondar.

2.4. Preparation of Plant Crude Extracts. Leaves of the plant were washed with tap water and air dried under shade at room temperature for two weeks. Then, it was chopped, powdered, and kept in an air tight container until needed for the extraction process. Then, the powder was extracted by the maceration technique with four solvents as follows: methanol (80\%), chloroform (99.5\%), ethyl acetate (99\%), and n-hexane (99\%). Ground and powdered plant materials were soaked with each solvent separately at 10:1 solvent-to sample ratio $(\mathrm{v} / \mathrm{w})$ [34-36].

A $120 \mathrm{~g}$ of powdered plant material was obtained, and $30 \mathrm{~g}$ was used for each solvent. Thus, $30 \mathrm{~g}$ powder was macerated in $300 \mathrm{~mL}$ of each solvent in extraction bottles, such that the level of the solvent was above that of the plant material. The macerated mixtures were then left on the shaker for $72 \mathrm{~h}$ at room temperature.

Each extract was filtered through Whatman No.1 filter paper and concentrated with a Buchi Rota vapor R-200 and then transferred to appropriately labeled vials and allowed to stand at room temperature to permit evaporation of residual solvents. Methanol extract was concentrated using a lyophilizer to remove water residue. After all, 5, 5, 5, and $4 \mathrm{~g}$ of crude methanolic, chloroform, ethyl acetate, and n-hexane extracts were obtained, respectively. Then, the extracts were stored under refrigeration at $4^{\circ} \mathrm{C}$ for further studies.

2.5. Qualitative Analysis of Phytochemicals. The presence of different phytochemical constituents of $C$. bonariensis was detected using standard procedures. The presence of phenolic compounds was detected using the protocol of Martin et al. [37]. Flavonoids, terpenoids, cardiac glycosides, alkaloids, saponins, and tannins were characterized using the method of Ayoola et al. [38]. Steroids [39] and anthraquinones [40] were also detected.

2.6. Screeningfor Antifungal Activity. Antifungal activities of different extracts were determined using the agar well diffusion assay [41]. The test pathogenic fungi (C. albicans, M. globosa, and M. furfur) were obtained from the University of Gondar Comprehensive Specialized Hospital. These pathogenic fungi were first grown on Sabouraud dextrose broth, incubated for 3 days at $29^{\circ} \mathrm{C}$. Fresh fungal cultures were spread on the surface of Sabouraud dextrose

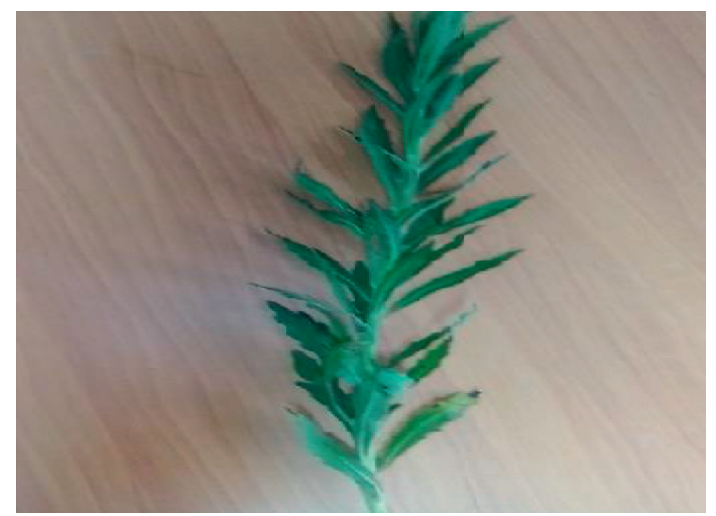

FIgURE 1: Image of C. bonariensis taken by Tamene Milkessa Jiru.

agar plates and incubated for 3 days at $29^{\circ} \mathrm{C}$. Wells were made in Sabouraud dextrose agar with the help of sterile cork borer keeping enough distance between them. About $100 \mathrm{mg} / \mathrm{mL}$ stock of each crude extract was prepared by dissolving $100 \mathrm{mg}$ of dried plant powder in $1 \mathrm{~mL}$ of $10 \%$ DMSO and added to the wells, while one well was supplemented with DMSO, which served as the negative control, and ketoconazole as the positive controls [42].The zones of inhibition were then measured after $72 \mathrm{~h}$ of the incubation period. All the experiments were conducted in triplicates.

2.7. Determination of MIC. Determination of MIC of each crude extract was performed using the broth microdilution method [43]. First, $100 \mu \mathrm{L}$ of Sabouraud dextrose broth was added to all the wells of a 96-well microtiter plate. Then, about $100 \mu \mathrm{L}$ of each dissolved crude extract $(100 \mathrm{mg} / \mathrm{mL})$ was added in the first well and serially diluted row by row to give $50,25,12.5,6.25,3.125,1.56,0.78,0.39$, and $0.19 \mathrm{mg} / \mathrm{mL}$, and $100 \mu \mathrm{L}$ of the mixture was discarded from the last row, thus leaving each diluted well with a volume of $100 \mu \mathrm{L}$, except for the positive and negative controls. The inocula of test strains prepared from fresh overnight cultures were adjusted to 0.5 McFarland standard, and $100 \mu \mathrm{L}$ was poured to the wells of a 96-well microtiter plate. Wells containing microbial suspensions, growth medium, as well as DMSO were used as negative control. Wells containing microbial suspensions, growth medium, and ketoconazole were used as positive control.

The microtiter plates were incubated at $29^{\circ} \mathrm{C}$ for $72 \mathrm{~h}$ for fungi, and then, $20 \mu \mathrm{L}$ of resazurin was added to each well to indicate respiratory activity, and a change in color from blue to pink would be determined after incubating it at $29^{\circ} \mathrm{C}$ for $24 \mathrm{~h}$. The MICs were the lowest concentration where no viability was observed after $24 \mathrm{~h}$ on the basis of metabolic activity. All the growth formation below the MIC or the growth of one or two colonies or film of growth will be discarded or disregarded [44, 45].

2.8. Determination of MFC. Minimum MFC is the lowest extract concentration that completely exterminates the microbial population. Microbial cells from the MIC test plates were subcultured on the fresh Sabouraud dextrose 
agar media for fungi. The plates were then incubated at $29^{\circ} \mathrm{C}$ for 3 days. Plates that did not show growth of the colony or 99.9\% reduction of CFU on the solid agar medium after subculturing were considered to be the MFC $[46,47]$. The experiments were carried out in triplicates.

2.9. Data Analysis and Interpretation. The data collected was entered to Microsoft Excel 2013 and transferred to SPSS version 20 for analysis. The experimental results were expressed as mean \pm standard deviation (SD) of three replicates. Where applicable, the data were subjected to one-way analysis of variance (ANOVA), and differences between samples were determined by the two-tailed $t$-test after Bonferroni error correction of the predictive value. $P$ values less than 0.05 will be considered statistically significant.

\section{Results}

3.1. Qualitative Analysis of Phytochemicals. In the current study, chloroform, ethyl acetate, hexane, and methanol extracts of the plant $C$. bonariensis were tested qualitatively for the presence of phytochemicals. All the plant extracts were found to contain steroids, terpenoids, phenols, saponins, tannins, alkaloids, anthraquinones, flavonoids, and glycosides.

3.2. Antifungal Activities. The result of agar well diffusion assay demonstrated that all extracts had different effects against all the tested fungi with the exception of crude extract using hexane which did not show any effect against M. furfur. A strong effect was observed with chloroform and hexane extracts on $C$. albicans $(32.60 \pm 4.69 \mathrm{~mm}$ and $27.00 \pm 1.00 \mathrm{~mm}$ ), respectively. While, the ethyl acetate and methanol extract showed the best effect $30.80 \pm 1.71 \mathrm{~mm}$ and $27.00 \pm 1.00 \mathrm{~mm}$, respectively, against $M$. furfur. Moreover, the ethyl acetate showed a considerable effect on $M$. globosa $(25.03 \pm 1.05 \mathrm{~mm})$ (Table 1$)$.

The comparison of the effect different extracts against each fungal pathogen was evaluated in the agar well diffusion assay. According to the result, even if the C. albicans showed a variable degree of susceptibility to all extracts, the best result was recorded by chloroform extract $(32.60 \pm 4.69 \mathrm{~mm})$, followed by ethyl acetate $(30.10 \pm 6.18 \mathrm{~mm})$. But the effects observed by both extracts were lower compared to ketoconazole $(44.40 \pm 1.69 \mathrm{~mm})$.

On the other hand, $M$. furfur was highly susceptible to ethyl acetate crude extract followed by methanol extract. These effects were more preferable, since there was no any effect produced by ketoconazole against $M$. furfur. Furthermore, M. globosa was sensitive to all extracts with variable degrees. The best effect was observed by ethyl acetate $(25.03 \pm 1.05 \mathrm{~mm})$ followed by methanol $(21.33 \pm 1.53 \mathrm{~mm})$. In addition, the effects made by all extracts were still better compared to the control ketoconazole $(11.00 \pm 0.00 \mathrm{~mm})$ (Table 1). No effect was exhibited by DMSO against each fungal pathogen that causes superficial infection.

Statistically, no significant difference result was seen against C. albicans between chloroform, ethyl acetate, and hexane extracts $(p<0.05)$, but there was a significant difference between those extracts and methanol extract as well as both positive and negative controls $(p<0.05)$. Concerning $M$. furfur, statistically significant higher result was seen by ethyl acetate, methanol, and chloroform extracts, compared to ketoconazole and DMSO $(p<0.05)$.

The result of data analysis indicated that there was no significant antimicrobial effect difference between ethyl acetate and methanol extracts against M. globosa; however, their effect was significantly different from ketoconazole $(p<0.05)$ (Table 1$)$. There was also no significance between extracts of chloroform and hexane.

3.3. Determination of MIC. The results recorded as the MIC values of the tested extracts against fungi varied from $0.19 \pm 0.00$ to $66.66 \pm 2.86 \mathrm{mg} / \mathrm{mL}$. Ethyl acetate was the best and powerful extract with the lowest MIC value of $0.19 \pm 0.00 \mathrm{mg} / \mathrm{mL}$ for all tested fungi followed by chloroform and methanol extracts with the MIC values ranging $(0.19 \pm 0.00$ to $0.78 \pm 0.00 \mathrm{mg} / \mathrm{mL})$ and $(0.84 \pm 0.68$ to $1.56 \pm 0.00 \mathrm{mg} / \mathrm{mL}$ ), respectively. On the contrary, the poor MIC value was recorded by hexane extract from $1.56 \pm 0.00$ to $66.66 \pm 2.86 \mathrm{mg} / \mathrm{mL}$ (Table 2).

3.4. Determination of MFC. Based on the result obtained, the MFC values of the tested extracts generally varied in the range from $0.19 \pm 0.00$ to $83.33 \pm 1.83 \mathrm{mg} / \mathrm{mL}$. Ethyl acetate was the most potent extract with a MFC value of $0.19 \mathrm{mg} / \mathrm{mL}$ for C. albicans and M. furfur. Higher $(0.39 \mathrm{mg} / \mathrm{mL}) \mathrm{MFC}$ was recorded against $M$. globosa by this extract. The lowest and highest MFC values recorded by chloroform and methanol extracts were $(0.19 \pm 0.00$ and $0.78 \pm 0.00 \mathrm{mg} / \mathrm{mL} ; 0.78 \pm 0.00$ and $3.12 \pm 0.00 \mathrm{mg} / \mathrm{mL}$ ) on C. albicans and $M$. globosa, respectively. Very high MFC value $(83.33 \pm 1.83 \mathrm{mg} / \mathrm{mL})$ was observed on $M$. furfur by hexane extract.

All extracts showed considerable effects on C. albicans. But the best was recorded by chloroform and ethyl acetate extracts at similar concentration $(0.19 \pm 0.00 \mathrm{mg} / \mathrm{mL})$. On the other hand, M. furfur and M. globosa could be killed by ethyl acetate extract at the concentrations of $0.19 \pm 0.00 \mathrm{mg} / \mathrm{mL}$ and $0.39 \pm 0.00 \mathrm{mg} / \mathrm{mL}$, respectively (Table 3 ).

\section{Discussion}

Medicinal plants are abundant sources of antimicrobial molecules; for this reason, a wide range of their extracts are used to treat several infections [48], and numerous works have been performed to examine the antimicrobial effects of the extracts from roots, stem, leaves, flowers, or seeds $[32,49,50]$, and the beneficial medicinal effects of plant materials typically result from the combination of secondary products present in plants. Many studies conducted in different parts of the world showed that leaves are used more than others parts of a plant [32, 51-54].

In this study, prior to testing antibacterial activities, crude extracts of $C$. bonariensis leaves were qualitatively tested for the presence of phytochemicals. All extracts were found to contain steroids, terpenoids, phenols, saponins, 
TABLE 1: Antifungal activities of different extracts determined using the agar well diffusion assay.

\begin{tabular}{lccc}
\hline Crude extracts & C. albicans & M. furfur & M. globosa \\
\hline Chloroform extract $^{\text {3. }} 32.60 \pm 4.69^{\mathrm{b}}$ & $20.63 \pm 0.65^{\mathrm{b}}$ & $12.33 \pm 0.58^{\mathrm{b}}$ \\
Ethyl acetate extract & $30.10 \pm 6.18^{\mathrm{b}}$ & $30.80 \pm 1.71^{\mathrm{a}}$ & $25.03 \pm 1.05^{\mathrm{a}}$ \\
Hexane extract & $27.00 \pm 1.00^{\mathrm{b}}$ & $0.00 \pm 0.00^{\mathrm{c}}$ & $12.67 \pm 0.58^{\mathrm{b}}$ \\
Methanol extract & $16.57 \pm 1.40^{\mathrm{c}}$ & $27.00 \pm 1.00^{\mathrm{a}}$ & $21.33 \pm 1.53^{\mathrm{a}}$ \\
KC & $44.40 \pm 1.69^{\mathrm{a}}$ & $0.00 \pm 0.00^{\mathrm{c}}$ & $11.00 \pm 0.00^{\mathrm{b}}$ \\
DMSO & $0.00 \pm 0.00^{\mathrm{d}}$ & $0.00 \pm 0.00^{\mathrm{c}}$ & $0.00 \pm 0.00^{\mathrm{c}}$ \\
\hline
\end{tabular}

The values of average zones of inhibitions are expressed as mean \pm SD $(n=3)$ within each column; means are significantly different $(p<0.05)$, unless they have a common letter. DMSO, dimethyl sulphoxide; KC, ketoconazole.

TABLE 2: MIC $(\mathrm{mg} / \mathrm{mL})$ value of each extract against fungi.

\begin{tabular}{lccc}
\hline Crude extracts & C. albicans & M. furfur & M. globosa \\
\hline Chloroform extract & $0.19 \pm 0.00$ & $0.52 \pm 0.22$ & $0.78 \pm 0.00$ \\
Ethyl acetate extract & $0.19 \pm 0.00$ & $0.19 \pm 0.0$ & $0.19 \pm 0.00$ \\
Hexane extract & $0.52 \pm 0.22$ & $66.66 \pm 2.86$ & $1.56 \pm 0.00$ \\
Methanol extract & $0.84 \pm 0.68$ & $0.65 \pm 0.22$ & $1.56 \pm 0.00$ \\
\hline
\end{tabular}

TABLE 3: MFC (mg/mL) value of each extract against skin infecting fungi.

\begin{tabular}{lccc}
\hline Crude extracts & C. albicans & M. furfur & M. globosa \\
\hline Chloroform extract & $0.19 \pm 0.00$ & $0.78 \pm 0.00$ & $1.56 \pm 0.00$ \\
Ethyl acetate extract & $0.19 \pm 0.00$ & $0.19 \pm 0.00$ & $0.39 \pm 0.00$ \\
Hexane extract & $0.52 \pm 0.22$ & $83.33 \pm 1.83$ & $3.12 \pm 0.00$ \\
Methanol extract & $0.78 \pm 0.00$ & $1.56 \pm 0.00$ & $3.12 \pm 0.00$ \\
\hline
\end{tabular}

Average MFC values are expressed as mean \pm SD $(n=3)$; analysis was performed with one-way ANOVA followed by the Bonferroni test.

tannins, alkaloids, anthraquinones, flavonoids, and glycoside, which means that the studied plant includes all these compounds that had contributed to its antimicrobial activity against the tested fungal pathogens. Secondary metabolites belonging to different phytochemicals have been reported from members of genus Conyza including alkaloids, volatile oils, terpenoids, phenols, flavonoids, and hydrolysable tannins [55].

In the current study, solvent extracts of leaves of C. bonariensis were used. The antimicrobial activity of chloroform, ethyl acetate, hexane, and methanol extracts from the plant $C$. bonariensis leaves were tested against three fungal pathogens that cause superficial infections. It was found that the plant had antimicrobial activity against those microbes. This finding was in line with the studies conducted by Shah et al. [56], Musembei and Joyce [57], and Mussin et al. [32]. The possible explanation for this could be the plant $C$. bonariensis is rich in phytochemical compounds with potential antimicrobial activities as confirmed from experiment.

In this study, all the crude extracts were applied against different fungal pathogens. Most of them showed different antimicrobial activities to the tested organisms. The possible reason for this different antimicrobial activity could be the susceptibility pattern of the pathogens and the differences in mechanism of actions of the metabolites in each solvent fraction, the method of extraction used, the different geographical and environmental conditions during the growth of the plant, and the age of the plant.

The current study revealed that ethyl acetate and hexane extract showed maximum and minimum average zones of inhibition, respectively. This result was in line with the study conducted by Shah et al. [56] at Pakistan who obtained similar results. The possible justification ethyl acetate could be the best solvent to extract active ingredients, which powerfully combat the tested microbes.

The average zones of inhibition formed by ethyl acetate, chloroform, methanol, and hexane extracts against C. albicans were $30.10 \pm 6.18 \mathrm{~mm}, \quad 32.60 \pm 4.69 \mathrm{~mm}$, $16.57 \pm 1.40 \mathrm{~mm}$, and $27.00 \pm 1.00 \mathrm{~mm}$, respectively. The finding of this study is a bit lower than Shah et al. [56] who obtained a higher inhibition effect of ethyl acetate, chloroform, and methanol extract with inhibitory zone of $35 \mathrm{~mm}, 28 \mathrm{~mm}$, and $25 \mathrm{~mm}$, respectively. Again, another better result was also reported by Shah et al. [58] from Pakistan on related species of plant with the maximum effect against $C$. albicans produced by chloroform, $n$-hexane, and ethyl acetate fraction with inhibitory zone of $45 \mathrm{~mm}, 40 \mathrm{~mm}$, and $33 \mathrm{~mm}$, respectively.

DMSO which was used as a control showed no effect against the growth each pathogenic fungi causing superficial infection. All pathogenic fungi studied grew in the absence of extract.

The results recorded as the MIC values of the tested extracts against C. albicans varied from 0.19 to $0.84 \mathrm{mg} / \mathrm{mL}$. According to the study conducted by Ahmed et al. [4] in Egypt on C. bonariensis, a MIC value of $>800 \mathrm{mg} / \mathrm{mL}$ against C. albicans was found which was poor compared to the present finding. This could be the difference in the methodology utilized. Similarly, the MFC values of the tested extracts against the three pathogenic fungi causing supercritical infections generally varied in the range from $0.19 \pm 0.00$ to $83.33 \pm \pm 1.83 \mathrm{mg} / \mathrm{mL}$.

\section{Conclusion}

This study investigated the antimicrobial activities of the plant $C$. bonariensis. The plant extracts showed antimicrobial activity when used against fungal pathogens. Results indicated that the ethyl acetate extract demonstrated significant antifungal activities against the growth of pathogenic fungi, but $n$-hexane showed less antibacterial activity against any of the test microbes relatively. This result can pave the way towards the move for the discovery of new efficacious, less toxic, and inexpensive plant-based medicines used for controlling pathogenic fungi causing superficial infections. Moreover, it might give the answer to the currently existing and newly emerging fear of multidrug resistance pathogenic microorganisms.

\section{Data Availability}

The data used to support the findings of this study are included within the article. 


\section{Disclosure}

YG performed the experiments as part of his master's thesis work.

\section{Conflicts of Interest}

The authors declare that they have no conflicts of interest.

\section{Authors' Contributions}

This work was carried out under the supervision of TMJ. TMJ also helped in editing the manuscript. Both authors read and approved the final manuscript.

\section{Acknowledgments}

The authors would like to acknowledge the Institute of Biotechnology, University of Gondar. Both authors are thankful to Abiyou Eniyew from Department of Biology, College of Natural and Computational Sciences, University of Gondar, for taxonomical identification and verification. Further thanks will go to Microbiology Laboratory, University of Gondar Comprehensive Specialized Hospital, for providing fungal strains.

\section{References}

[1] World Health Organization (WHO), 2002-2005: Traditional Medicine Strategy, World Health Organization, Geneva, Switzerland, 2002.

[2] Q. W. Shi, L. G. Li, C. H. Huo, M. L. Zhang, and Y. F. Wang, "Study on natural medicinal chemistry and new drug development," Chinese Traditional and Herbal Drugs, vol. 41, pp. 1583-1589, 2010.

[3] T. Seifu, "Ethno botanical and Ethno pharmaceutical studies on medicinal plants of Chifra District, Afar Region, North Eastern Ethiopia," MSc Thesis, Addis Ababa University, Addis Ababa, Ethiopia, 2004.

[4] I. Ahmed, H. Mona, and M. Soheir, "Genetic profiling, chemical characterization and biological evaluation of two Conyza species growing in Egypt," Journal of Applied Pharmaceutical Science, vol. 2, pp. 54-61, 2012.

[5] M. Ashebir and Ashenafi, "Evaluation of the antibacterial activity of crude preparation of Zingiber officinalae ("Zinjibl"). Echinops spp. ("kebericho"), Coriandrum sativum ("dimbilal") and Cymbopogan citratus ("tej sar") on some food borne pathogens," Ethiopian Journal of Health Sciences, vol. 9, pp. 33-40, 1999.

[6] M. Kaba, "Utilization of plant medicine for the treatment of health problems: the case of Oromo, Illubabur zone Western Ethiopia," The Ethiopian Journal of Health Development, vol. 10, pp. 161-162, 1996.

[7] K. D. Kassaye, A. Amberbir, B. Gatchew, and Y. Mussema, "A historical overview of traditional medicine practices and policy in Ethiopia," The Ethiopian Journal of Health Development, vol. 20, pp. 127-134, 2006.

[8] Y. Yeshiwas, E. Tadele, and W. Tiruneh, "The dynamics of medicinal plants utilization practice nexus its health and economic role in Ethiopia," International Journal of Biodiversity Conservevation, vol. 11, pp. 31-47, 2019.

[9] R. Singh, "Medicinal Plants," Journal of Plant Science, vol. 3, pp. 50-55, 2015.
[10] Y. Habtamu, T. Eguale, A. Wubete, and T. Sori, "In vitro antimicrobial activity of selected Ethiopian medicinal plants against some bacteria of veterinary importance," African Journal of Microbiology Research, vol. 4, pp. 1230-1234, 2010.

[11] B. Chekesa and Y. Mekonnen, "Antibacterial activity of Moringas tenopetala against some human pathogenic bacterial strains," Science, Technology and Arts Research Journal, vol. 4, pp. 190-198, 2015.

[12] E. A. Gantwerker and D. B. Hom, "Skin: histology and physiology of wound healing," Facial Plastic Surgery Clinics of North America, vol. 19, no. 3, pp. 441-453, 2011.

[13] A. Massiha and P. Z. Muradov, "Comparison of antifungal activity of extracts of ten plant species and griseofulvin against human pathogenic dermatophytes," Journal of Research in Medical Sciences, vol. 17, Article ID e2096, 2015.

[14] L. C. Shao, C. Q. Sheng, and W. N. Zhang, "Recent advances in the study of an antifungal lead compound with new chemical scaffolds," Acta Pharmaceutica Sinica, vol. 42, no. 11, pp. 1129-1136, 2007.

[15] M. A. Pfaller, S. A. Messer, R. J. Hollis et al., "Variation in susceptibility of bloodstream isolates of Candida glabrata to fluconazole according to patient Age and geographic location in the United States in 2001 to 2007," Journal of Clinical Microbiology, vol. 47, no. 10, pp. 3185-3190, 2009.

[16] G. Garber, "An overview of fungal infections," Drugs, vol. 61, no. 1, pp. 1-12, 2001.

[17] A. N. B. Ellepola and L. P. Samaranayake, "Oral candidal infections and antimycotics," Critical Reviews in Oral Biology \& Medicine, vol. 11, no. 2, pp. 172-198, 2000.

[18] A. Geyid, D. Abebe, A. Debella et al., "Screening of some medicinal plants of Ethiopia for their anti-microbial properties and chemical profiles," Journal of Ethnopharmacology, vol. 97, no. 3, pp. 421-427, 2005.

[19] D. M. Pramila, R. Xavier, K. Marimuthu et al., "Phytochemical analysis and antimicrobial potential of methanolic leaf extract of peppermint (Mentha piperita: lamiaceae)," Journal of Medicinal Plants Research, vol. 6, no. 2, pp. 331-335, 2012.

[20] A. I. Husein, M. S. Ali-Shtayeh, R. M. Jamous, S. Y. A. Zaitoun, W. J. Jondi, and N. A. A. Zatar, "Antimicrobial activities of six plants used in traditional Arabic Palestinian herbal medicine," African Journal of Microbiology Research, vol. 8, no. 38, pp. 3501-3507, 2014.

[21] N. Morishita and Y. Sei, "Microreview of pityriasis versicolor and Malassezia species," Mycopathologia, vol. 162, no. 6, pp. 373-376, 2006.

[22] A. Prohic and L. Ozegovic, "Malassezia species isolated from lesional and non-lesional skin in patients with pityriasis versicolor," Mycoses, vol. 50, no. 1, pp. 58-63, 2007.

[23] D. Weedon, Skin Pathology, p. 1172, 2nd edition, Churchill Livingstone, 2002.

[24] G. A. Turner, M. Hoptroff, and C. R. Harding, "Stratum corneum dysfunction in dandruff," International Journal of Cosmetic Science, vol. 34, no. 4, pp. 298-306, 2012.

[25] B. I. Ro and T. L. Dawson, "The role of sebaceous gland activity and scalp microfloral metabolism in the etiology of seborrheic dermatitis and dandruff," Journal of Investigative Dermatology Symposium Proceedings, vol. 10, no. 3, pp. 194-197, 2005.

[26] R. Vijayakumar, C. Muthukumar, T. Kumar, and R. Saravanamuthu, "Characterization of Malassezia furfur and its control by using plant extracts," Indian Journal of Dermatology, vol. 51, no. 2, pp. 145-148, 2006.

[27] C. W. Saunders, A. Scheynius, and J. Heitman, "Malassezia fungi are specialized to live on skin and associated with 
dandruff, eczema, and other skin diseases," PLoS Pathogens, vol. 6, 2012.

[28] B. Sommer, D. P. Overy, and R. G. Kerr, "Identification and characterization of lipases from Malassezia restricta, a causative agent of dandruff," FEMS Yeast Research, vol. 15, no. 7, pp. 1-8, 2015.

[29] G. Santos, A. C. Francischini, É. Blainski, A. Gemelli, and M. d. F. P. S. Machado, "Aspectos da biologia e da germinação da buva," in Buva: Fundamentos e Recomendações para Manejo, J. Constantin, R. S. Oliveira, and A. M. Oliveira, Eds., pp. 11-26, 2013.

[30] W. Hanwen and E. H. Graham, "The biology of Australian weeds 49. Conyza bonariensis (L.) Cronquist," Plant Protection Quarterly, vol. 22, pp. 122-131, 2007.

[31] C. Favila and M. Antonio, "Chemical and biological study of conyza bonariensis (L.) Cronquist (Asteraceae)," Thesis dissertation, Federal University of Santa Maria, Santa Maria, Brazil, 2006.

[32] J. E. Mussin, P. Manzano, M. Mangiaterra, and G. Giusiano, "Inhibitory activity of Conyza bonariensis (L.) Cronquist tincture against fungi and bacteria causing superficial infections," Revista Cubana de Plantas Medicinales, vol. 22, no. 3, pp. 1-12, 2017.

[33] Central Statistical Agency (CSA), HCE 2016 Statistical Report Amhara Region, Central Statistical Agency (CSA), Addis Ababa, Ethiopia, 2016

[34] B. Barkatullah, I. Muhammad, and N. Muhammad, "Evaluation of Zanthoxylum armatum DC for in-vitro and in-vivo pharmacological screening," African Journal of Pharmacy and Pharmacology, vol. 5, no. 14, pp. 1718-1723, 2011.

[35] H. Khan, M. Saeed, M. A. Khan et al., "Antimalarial and free radical scavenging activities of rhizomes of Polygonatum verticillatum supported by isolated metabolites," Medicinal Chemistry Research, vol. 21, no. 7, pp. 1278-1282, 2011.

[36] N. Raziq, N. Muhammad, K. A. Chishti, M. F. Saeed, S. Rahman, and H. Khan, "Correlation of the antioxidant capacity with the phenolic contents of Hypericum monogynum and Hypericum perforatum," African Journal of Pharmacy and Pharmacology, vol. 5, pp. 1872-1876, 2011.

[37] M. Á. Martín, E. Fernández-Millán, S. Ramos, L. Bravo, and L. Goya, "Cocoa flavonoid epicatechin protects pancreatic beta cell viability and function against oxidative stress," Molecular Nutrition \& Food Research, vol. 58, no. 3, pp. 447-456, 2014.

[38] G. A. Ayoola, H. A. B. Coker, S. A. Adesegun et al., "Phytochemical screening and antioxidant activities of some selected medicinal plants used for malaria therapy in Southwestern Nigeria," Tropical Journal of Pharmaceutical Research, vol. 7, pp. 1019-1024, 2008.

[39] S. Guettaf, N. Abidli, S. Kariche, L. Bellebcir, and H. Bouriche, "Phytochemical screening and antioxidant activity of aqueous extract of Genista Saharae (Coss. and Dur.)," Der Pharmacia Lettre, vol. 8, no. 1, pp. 50-60, 2016.

[40] O. O. Aiyelaagbe and P. M. Osamudiamen, "Phytochemical screening for active compounds in Mangifera indica leaf from Ibadan, Oyo State," Plant Sciences Research, vol. 2, no. 1, pp. 11-13, 2009.

[41] Z. S. Nisar, A. K. Mir, M. Naveed, A. Sadia, and R. Abdur, "Antimicrobial and phytotoxic profile of Conyza sumatrensis," Middle-East Journal of Medicinal Plants Research, vol. 1, pp. 44-50, 2012.
[42] D. N. Muanza, B. W. Kim, K. L. Euler, and L. Williams, "Antibacterial and antifungal activities of nine medicinal plants from zaire," International Journal of Pharmacognosy, vol. 32, no. 4, pp. 337-345, 1994.

[43] I. Wiegand, K. Hilpert, and R. E. W. Hancock, "Agar and broth dilution methods to determine the minimal inhibitory concentration (MIC) of antimicrobial substances," Nature Protocols, vol. 3, no. 2, pp. 163-175, 2008.

[44] R. J. W. Lambert and J. Pearson, "Susceptibility testing: accurate and reproducible minimum inhibitory concentration (MIC) and non-inhibitory concentration (NIC) values," Journal of Applied Microbiology, vol. 88, no. 5, pp. 784-790, 2000.

[45] J. M. Andrews, "Determination of minimum inhibitory concentrations," Antimicrobial Chemotherapy, vol. 48, no. 6, pp. 5-16, 2001

[46] N. S. Ncube, A. J. Afolayan, and A. I. Okoh, "Assessment techniques of antimicrobial properties of natural compounds of plant origin: current methods and future trends," African Journal of Biotechnology, vol. 7, no. 12, pp. 1797-1806, 2008.

[47] S. C. Ugoh and I. M. Jaruma, "Phytochemical screening and antibacterial activity of the fruit and leaf extract of Tamarindus indica (Linn)," Report and Opinion, vol. 5, no. 8, pp. 18-27, 2013.

[48] J. J. M. T. Renisheya, M. Johnson, U. M. Mary, and A. Arthy, "Antibacterial activity of ethanolic extracts of selected medicinal plants against human pathogens," Asian Pacific Journal of Tropical Biomedicine, vol. 1, no. 1, pp. S76-S78, 2011.

[49] D. Abu-Shanab, D. Adwan, D. Abu-Safiya, N. Jarrar, and K. Adwan, "Antibacterial activities of some plant extracts utilized in popular medicine in Palestine," Turkish Journal of Biology, vol. 28, no. 2-4, pp. 99-102, 2005.

[50] F. Abbassi and K. Hani, "In vitroantibacterial and antifungal activities ofRhus tripartitumused as antidiarrhoeal in Tunisian folk medicine," Natural Product Research, vol. 26, no. 23, pp. 2215-2218, 2012.

[51] A. Togola, D. Diallo, S. Dembélé, T. H. Barset, and B. S. Paulsen, "Ethnopharmacological survey of different uses of seven medicinal plant $s$ from Mali (West Africa) in the regions Doila, Kolokani and Siby," Journal of Ethnobiology and Ethnomedicine, vol. 1, no. 7, pp. 1-9, 2005.

[52] S. M. Maregesi, O. D. Ngassapa, L. Pieters, and A. J. Vlietinck, "Ethnopharmacological survey of the Bunda district, Tanzania: plants used to treat infectious diseases," Journal of Ethnopharmacology, vol. 113, no. 3, pp. 457-470, 2007.

[53] Y. Yineger and D. Yewhalaw, "Traditional medicinal plant knowledge and use by loc al healers in Sekoru District, Jimma Zone, Southwestern Ethiopia," Journal of Ethnobiology and Ethnomedicine, vol. 3, no. 24, 2007.

[54] T. H. Bekalo, S. D. Woodmatas, and Z. A. Woldemariam, "An ethnobotanical study of medicinal plants used by local people in the lowlands of Konta Special Woreda, southern nations, nationalities and peoples regional state, Ethiopia," Journal of Ethnobiology and Ethnomedicine, vol. 5, no. 26, pp. 1-15, 2009.

[55] D. Shahwar, M. A. Raza, A. Saeed et al., "Antioxidant potential of the extracts of Putranjiv aroxburghii, Conyza bonariensis, Wood for diafruiticosa and Seneciochrys anthemoids," African Journal of Biotechnology, vol. 11, no. 18, pp. 4288-4295, 2012.

[56] N. Z. Shah, N. Muhammad, S. Azeem, A. Z. Khan, M. Samie, and H. Khan, "Antimicrobial and phytotoxic properties of Conyza bonariensis," Pharmacy and Pharmacology Research, vol. 1, no. 1, pp. 8-11, 2013. 
[57] R. Musembei and K. J. Joyce, "Chemical composition and antibacterial activity of essential oil from Kenyan Conyza bonariensis L. Cronquist," Science Letters Journal, vol. 5, pp. 180-185, 2017.

[58] N. Z. Shah, N. Muhammad, S. Azeem, and A. Rauf, "Preliminary phytochemical and anti-radical profile of Conyza sumatrensis," Middle-East Journal Medicinal Plant Research, vol. 1, no. 1, pp. 05-08, 2012. 